\title{
Should given information come before new? Yes and no
}

\author{
CHARLES CLIFTON, JR. and LYN FRAZIER \\ University of Massachusetts, Amherst, Massachusetts
}

\begin{abstract}
It has been noted for some time that given information tends to be placed before new information (e.g., Clark \& Clark, 1977). To determine whether this holds generally, double-object and NP-PP sentences like the following were tested in two speeded acceptability judgment experiments. (1A) The senator mailed the woman a report. (1B) The senator mailed a woman the report. (1C) The senator mailed the report to a woman. (1D) The senator mailed a report to the woman. Given-before-new (or definite before indefinite) ordering facilitated processing for double-object structures, with (1A) processed faster and accepted more often than (1B), but did not facilitate processing of (1C) relative to (1D) in NP-PP structures. A third self-paced reading experiment showed that the advantage of the definite-before-indefinite new ordering holds for constructions with a shifted NP (The senator mailed to the woman a report) but also showed that facilitation from having a definite NP immediately after the verb was limited to cases where the two arguments of a verb contrast in definiteness. The results suggest that the presumed given-before-new preference is not general, but is instead limited to certain constructions and is based on the language comprehension system being sensitive to the requirements of language production.
\end{abstract}

Natural languages have been claimed to tend to place given constituents before new (Clark \& Clark, 1977; Clark \& Haviland, 1977; Halliday, 1967). Some theorists (e.g., Clark \& Haviland, 1977) attribute this preference to comprehension processes that reflect the needs of the listener/reader: Ordering given information before new aids the listener because it allows the listener to search memory for the antecedent of given information before new information is encountered. Ordering new information before given creates a memory problem, because new information must be held in abeyance while the listener waits for the given information with which it must be integrated. Other theorists (e.g., Arnold, Wasow, Losongco, \& Ginstrom, 2000; Wasow, 1997b; and references therein) emphasize the needs of the speaker: New information is less accessible than given information, and delaying the production of new information while uttering given information gives the speaker additional time to access and plan how to express the new information.

\section{Production Preferences}

It is possible that the given-before-new preference holds for both production and comprehension. This could be because separate production and comprehension processes exist, reflecting the distinct needs of the listener

This research was supported by Grant HD-18708 from the National Institutes of Health to the University of Massachusetts, Amherst. The authors thank Mohamed Mohamed for discussion of the research reported and three anonymous reviewers for their constructive comments. Correspondence should be addressed to C. Clifton, Jr., Department of Psychology, University of Massachusetts, Amherst, MA 01003 (e-mail: cec@psych.umass.edu). and the speaker. Alternatively, it could be because one preference is fundamental and the other is derived. For instance, an underlying production preference could result in given-before-new constructions being high in frequency and therefore easily comprehended. Evidence for a given-before-new preference in production does exist. Arnold et al. (2000) show in a spoken-language corpus study and in a two-person communication experiment that there is a preference to produce a discourse-new phrase late in a sentence, after a discourse-given phrase. They show a similar effect for the length ("heaviness") of the phrase: Relatively heavy phrases tend to occur late in utterances. They suggest that these effects reflect constraints on planning and production, so that less available phrases are produced later. Earlier work by Wasow (1997b) indicated that the relative rather than the absolute heaviness of phrases determines where they appear in utterances. Wasow (1979b) also showed that the frequency of shifting a phrase to a late position in an utterance is not reduced in cases where shifting would prolong ambiguity, as should happen if shifts are for the benefit of the listener/reader rather than the speaker/writer.

Experimental research by Bock and Warren (1985) supports the suggestion that where phrases appear in an utterance reflects production processes. Examining errors in sentence recall, Bock and Warren demonstrated a tendency for people to recall more imageable noun phrases (NP) earlier in a sentence and less imageable ones later. In particular, they observed a tendency to recall more imageable NPs as grammatical subjects (rather than grammatical objects), even if this entailed a change in sentence form between active and passive. They further observed a tendency to recall more imageable NPs as the NP im- 
mediately after the verb than in the second object position of dative sentences (requiring a change to an NP-NP form when the goal or recipient was more imageable than the direct object, and a change to an NP-PP [prepositional phrase] form when the direct object was more imageable than the goal/recipient). They argued that conceptual accessibility governs production: More accessible elements are produced at higher positions in a grammatical hierarchy. ${ }^{1}$ Bock and Warren manipulated accessibility by varying the imageability of nouns (more imageable, more accessible), but givenness could also increase accessibility.

\section{Comprehension Needs}

A number of studies of sentence comprehension also show a preference for the given-before-new ordering. However, most of the evidence in fact demonstrates a preference for grammatical subjects to be given and grammatical objects (or other verb phrase-internal constituents) to be new. Furthermore, the existing research does not actually manipulate discourse givenness, but instead manipulates the definiteness of NPs. A given NP is typically expressed as a definite NP, and a new NP as indefinite. It is possible to assume that a reader or listener will honor this association by treating a definite NP as given. We will accept this assumption provisionally, referring to given/new $N P s$ when we wish to emphasize presumed discourse status (and availability) and definite/indefinite NPs when we are describing the usage in a sentence, but we will also evaluate the assumption in Experiment 2.

Kaan (1998) used a sentence-interpretation task to show that subject-before-object preferences in Dutch are stronger when an extracted NP is more definite (hence, more likely to be taken as given than the nonextracted NP, compared with when the extracted NP is less definite). For example, in (1), welke bioloog ("which biologist") is ambiguously subject or object of the embedded clause. Under the subject analysis, the questioned NP is extracted from a position (denoted by $\mathrm{t}$, trace) before the other NP; under the object analysis, the questioned NP is extracted from the second NP position. Participants in a completion task indicated whether they interpreted the extracted NP welke bioloog to be the subject or the object of the embedded verb by supplying a singular versus plural auxiliary verb in place of the Their responses indicated that they more frequently interpreted the extracted NP to be the subject when the other phrase delenkele scheikundigen was indefinite (1A) than when the other phrase was definite (1B). The $(\mathrm{t})$ notation indicates the sites from which the NP could have been extracted.

1A. Men wilde weten welke bioloog $\mathrm{b}_{\mathrm{i}}(\mathrm{t})_{\mathrm{i} \text {-subject }}$ enkele scheikundigen $(\mathrm{t})_{\mathrm{i} \text {-object }}$ geholpen ( $89 \%$ subject).

One wanted to know which biologist ${ }_{i}(t)_{i-s u b j e c t}$ some chemists $(t)_{i-o b j e c t}$ had helped.

1B. Men wilde weten welke bioloog $(t)_{i \text {-subject }}$ de

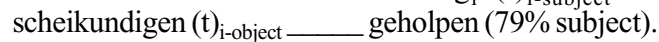

One wanted to know which biologist $\mathrm{i}_{\mathrm{i}}(\mathrm{t})_{\mathrm{i} \text {-subject }}$ the chemists $(t)_{\text {i-object }}$ had helped.
In a fragment completion study, Carlson (2002) found that the final NP was more likely to be treated as the subject of a second clause rather than the second of two conjoined NPs when it was definite (2A) than when it was indefinite (2B) (48\% vs. $20 \%$ of the time).

2A. John met a doctor at the café and the dentist

2B. John met a doctor at the café and a dentist

This difference suggests that a definite NP is preferred over an indefinite NP as the subject of a clause, thus offering an account of the comprehension speed effects reported by Henstra (1996, Experiment 9). Henstra observed slower reading times when one NP was indefinite and the other was definite (3A) than when both were indefinite (3B). Although this may simply reflect faster reading times for conjoined constructions when they are parallel in form (Frazier, Munn, \& Clifton, 2000), it might also reflect the preference observed by Carlson for readers to take definite NPs as clausal subjects. Since introducing a new clause results in a more complex syntactic structure than does simply conjoining two NPs, slower reading would presumably result if making the second NP definite encourages taking it to be the subject of a conjoined clause.

3A. The lecturer met a secretary and the professor ...

3B. The lecturer met a secretary and a professor ...

Although there does seem to be a preference in comprehension for a subject NP to be at least as definite as an object NP, the conclusion that there is a general preference in comprehension (or production) for given phrases to appear before new ones goes far beyond the available data. For instance, it may simply be that subjects are default topics, and topics are generally definite and given. Furthermore, it should be noted that other factors may create a preference for new phrases to occur before old. Some such factors are grammatical. For example, though topics tend to occur in early positions in a sentence, so do interrogative constituents. Consider (4):

4. Who left at precisely twelve o'clock?

Presupposition: X left at precisely twelve o'clock.

If a presupposition is considered given (as is common; cf. Clark \& Clark, 1977, for example), the given information in (4) follows the new information. Other factors may involve matters of performance. For instance, it appears that the preference to produce heavy constituents late in an utterance (Arnold et al., 2000) can result in the reduction or elimination of the preference to produce given information before new, and could affect the apparent comprehension preference for given-before-new.

\section{Beyond Subject and Object}

The research reported in the present paper examines an instance in which comprehension of given-beforenew sentences is facilitated when the phrases involved are not subject and object but are instead different comple- 
ments of the verb. It addresses this question by replicating and extending research reported by Beckman (1996), who investigated ambiguous double-object questions like (5), where (t) indicates potential extraction sites for the wh-phrase:

5A. Which patient did the nurse bring $\left(\mathrm{t}_{\text {goal }}\right)$ the doctor $\left(t_{\text {theme }}\right)$ ?

5B. Which patient did the nurse bring $\left(\mathrm{t}_{\text {goal }}\right)$ a doctor $\left(\mathrm{t}_{\text {theme }}\right)$ ?

Beckman showed that readers prefer the extracted NP which patient to be the "theme" or direct object when the postverbal NP is definite, as in (5A), but prefer the extracted NP to be the "goal" or indirect object when the postverbal NP is indefinite, as in (5B). Assuming that a definite NP is more definite than a which-NP, which is in turn more definite than an indefinite NP, this result indicates that more definite (more given) NPs are realized before less definite ones, as is illustrated in (6):

6A. Bring the doctor (which patient).

6B. Bring (which patient) a doctor.

Beckman (1996) also reported a speeded whole-sentence reading study, in which participants indicated whether they understood a sentence ("got it"). Sentences like (7A), in which a definite NP appeared before an indefinite NP, were understood faster and more often $(1,051 \mathrm{msec}, 98 \%$ of the time) than sentences like (7B) (1,152 msec, $89 \%$ ).

7A. The pitcher threw the umpire a ball.

7B. The pitcher threw an umpire the ball.

Beckman proposed the definiteness asymmetry constraint in (8) to account for both of these findings:

8. The definiteness of $\mathrm{NP}_{2}$ in a double-object construction of the form $\mathrm{V}-\mathrm{NP}_{1}-\mathrm{NP}_{2}$ must not exceed that of $\mathrm{NP}_{1}$.

In addition to replicating the latter finding, the present research extends it by including dative sentences with an NP-PP structure as well as double-object sentences like (7). It is possible that NP-PP sentences will show a preference for given-before-new, just like doubleobject sentences. Such a result would be expected if the given-before-new preference reflects reader/listener needs, such as the previously discussed need to minimize holding new information in memory while waiting for material that permits its interpretation. It is also possible that given-before-new is too broad a generalization, one that only applies to certain structures such as the double-object structure, and that it will not apply to all structures.

We note that in both the corpus frequency and the sentence production results of Arnold et al. (2000), NP-PP (theme-goal) constructions are substantially more frequent than double-object NP-NP (goal-theme) constructions (holding phrase length constant) when the theme is definite and the goal/recipient is indefinite. However (again holding phrase length constant), the frequency of
NP-PP and NP-NP double-object constructions is more nearly equal when the theme is indefinite and the goal/ recipient is definite. Readers and listeners may be sensitive to the relative frequency of different constructions, so that they would view an NP-NP double-object construction in which the goal/recipient $\left(\mathrm{NP}_{1}\right)$ is new and the theme $\left(\mathrm{NP}_{2}\right)$ is given as notably infrequent and hence difficult to process. Alternatively, and more interestingly from our point of view, it is possible that readers and listeners are directly responsive to whatever principles discourage speakers from producing double-object constructions with a given theme and a new goal/recipient. It may be that speakers and writers have a baseline preference for the NP-PP construction; it can be viewed as the "unmarked" construction, which justifies producing it in the general case. This preference can be overcome only when the theme is notably inaccessible (very long or very new and unfamiliar). In either case, readers may have difficulty comprehending NP-NP double-object constructions in which the first NP is new and the second given. Since speakers/writers frequently and justifiably produce NP-PP structures in which the NP is new and the PP contains a given NP, readers may not have such difficulty with such NP-PP constructions.

In Experiment 1, we obtained speeded acceptability judgments of sentences like those in (9) (where DNP = definite NP, INP = indefinite NP, DPP = PP with a definite NP, IPP = PP with an indefinite NP):

9A. The senator mailed the woman a report.

9B. The senator mailed a woman the report.

(DNP-INP)

9C. The senator mailed the report to a woman.

(INP-DNP)

(DNP-IPP)

9D. The senator mailed a report to the woman.

(INP-DPP)

A general given-before-new preference predicts an advantage in both definite-before-indefinite forms (9A, 9C) relative to their indefinite-before-definite counterparts $(9 \mathrm{~B}, 9 \mathrm{D})$. If the given-before-new preference is limited to double-object structures (which is consistent with Beckman's, 1996, phrasing of the definiteness asymmetry constraint and with the production-based process sketched above), there should be an advantage of (9A) over (9B), but not of (9C) over (9D).

\section{EXPERIMENT 1}

\section{Method}

Materials. Sixteen quadruples like (9) were constructed on the basis of Beckman's original sentence set. Two forms (9A, 9B) contained double-object structures; two (9C, 9D) contained their prepositional phrase counterparts. Two (9A, 9C) obeyed given-before-new (definite before indefinite) and two (9B, 9D) contained new-beforegiven constituents. All sentences for Experiment 1 appear in Appendix A. Counterbalancing procedures were used so that, across the full experiment, each experimental sentence was tested equally often in each of the four versions.

The 16 experimental items were embedded in two different lists of items. The first list contained 78 sentences or 2-sentence discourses 
in all, 36 of which were unacceptable in some way (subject-verb number disagreement, missing or extra arguments, improper tense in ellipsis or in successive sentences, anomalous arguments, etc.). The second list contained 94 sentences or discourses in all, including 16 items designed to test whether animate NPs in general prefer to be definite (to be briefly discussed below). In each list, two filler items were similar in form to the experimental items shown in (9). They were accidental residues of a planned six-condition, 18 -item experiment, but were not included in the properly counterbalanced design used for the 16 experimental items. Including the data from these 2 filler items did not change the results of the data analyses.

Participants and Procedure. Two independent groups of 48 University of Massachusetts undergraduates were tested individually in sessions of approximately $25 \mathrm{~min}$. The first group was tested on the first list of sentences and discourses described above, and the second group on the second list.

A session began with instructions and a 6-item practice list. Each sentence or discourse appeared as a whole on a computer monitor, and the participant was instructed to pull a trigger with the right hand if the sentence or discourse was acceptable or normal, and a trigger with the left hand if it was unacceptable, ungrammatical, or anomalous. The participants were told to keep their hands on the triggers at all times and to respond as quickly as they could while maintaining accuracy. They were told not to insist on high literary quality to accept a sentence, but simply to reject sentences that were clearly unacceptable. The 6 practice sentences were then presented and used as illustrations of what was acceptable and unacceptable. Following that, the 78 or 94 sentences of the experimental list were presented in individually randomized order. No questions were asked of the sentences, nor was any accuracy feedback given.

\section{Results}

Mean response times (RTs) and the proportions of "accept" responses $(\mathrm{P})$ appear in Table 1 . RTs over $8,000 \mathrm{msec}$ or greater than $2 S D$ above a participant's mean RT were truncated at the cutoff value ( $6 \%$ of all responses). ${ }^{2}$ Both RTs and proportion "accept" were subjected to analyses permitting generalization to participants $\left(F_{1}\right)$ and to items $\left(F_{2}\right)$.

The critical statistical result was a highly significant interaction: Whereas definite-before-indefinite was accepted more quickly and more often than indefinitebefore-definite for the double-NP structure (Conditions 1 and 2), the opposite held for the NP-PP structure [RT, $F_{1}(1,94)=62.61, M S_{\mathrm{e}}=3,910,190, p<.001 ; F_{2}(1,15)=$ $51.40, M S_{\mathrm{e}}=248,618, p<.001 ; \mathrm{P}($ accept $), F_{1}(1,94)=$ $54.68, M S_{\mathrm{e}}=0.008, p<.001 ; F_{2}(1,1)=13.38, M S_{\mathrm{e}}=$ $0.036, p<.002]$. Simple effects tests indicated that the definite-before-indefinite order resulted in significantly faster responses in the double-NP construction $\left[t_{1}(94)=\right.$

Table 1

Mean Response Times (RTs, in Milliseconds) and Proportion Accepted (P): Experiment 1

\begin{tabular}{|c|c|c|c|c|c|c|c|c|}
\hline & \multicolumn{8}{|c|}{ Condition } \\
\hline & \multicolumn{2}{|c|}{ DNP-INP } & \multicolumn{2}{|c|}{ INP-DNP } & \multicolumn{2}{|c|}{ DNP-IPP } & \multicolumn{2}{|c|}{ INP-DPP } \\
\hline & RT & $\mathrm{P}$ & $\mathrm{RT}$ & $\mathrm{P}$ & $\mathrm{RT}$ & $\mathrm{P}$ & $\mathrm{RT}$ & $\mathrm{P}$ \\
\hline Group 1 & 3,371 & .911 & 4,180 & .729 & 3,533 & .885 & 3,171 & .938 \\
\hline Group 2 & 3,524 & .878 & 4,376 & .701 & 4,041 & .860 & 3,537 & .941 \\
\hline Overall & 3,442 & .896 & 4,274 & .716 & 3,792 & .870 & 3,344 & .943 \\
\hline
\end{tabular}

7.97, $\left.p<.001 ; t_{2}(15)=5.92, p<.001\right]$ as well as more frequent acceptances $\left[t_{1}(94)=6.85, p<.001 ; t_{2}(15)=\right.$ $3.66, p<.002]$. The preference for indefinite-beforedefinite in the NP-PP construction was also significant $\left[\mathrm{RT}, t_{1}(94)=4.49, p<.001 ; t_{2}(15)=2.60, p<.05\right.$; $\mathrm{P}($ accept $), t_{1}(94)=3.20, p<.002$, but $t_{2}(15)=2.03$, $p=.06]$.

Overall, the double-NP structure was responded to more slowly and accepted less frequently than the NP-PP structure [RT, $F_{1}(1,94)=14.30, M S_{\mathrm{e}}=1,419,620, p<$ $.001 ; F_{2}(1,15)=4.52, M S_{\mathrm{e}}=604,334, p<.005 ; \mathrm{P}($ accept $)$, $F_{1}(1,94)=27.79, M S_{\mathrm{e}}=0.008, p<.001 ; F_{2}(1,15)=$ $\left.5.22, M S_{\mathrm{e}}=0.063, p<.04\right]$. There was an overall tendency, not always significant in the items analyses, for the definite-before-indefinite order to result in faster responses and more frequent acceptances than the indefinitebefore-definite order [RT, $F_{1}(1,94)=9.48, M S_{\mathrm{e}}=372,095$, $p<.003$, but $F_{2}(1,15)=2.48, M S_{\mathrm{e}}=509,515, p>.13$; $\mathrm{P}($ accept $), F_{1}(1,94)=9.11, M S_{\mathrm{e}}=0.030, p<.003$; $\left.F_{2}(1,15)=4.62, M S_{\mathrm{e}}=0.022, p<.05\right]$. No interactions with groups were significant.

\section{Discussion}

The results clearly indicate that there is an advantage for given-before-new in double-object sentences, but that this advantage does not extend to the NP-PP structure. It appears possible that there is a preference among NP-PP sentences for having new information (indefinite) presented before given (definite), but it is not as consistent a preference as the one observed for definitebefore-indefinite in the NP-NP structure.

Descriptively, the results are generally consistent with the suggestion that there is a preference for sentences with definite goal/recipient NPs. Since all the goal/recipients were human NPs, and all the themes were nonhuman NPs, the results are equally consistent with the suggestion that there is a preference for human NPs to be definite. Neither suggestion explains why the effect is so much clearer for double-object than for NP-PP sentences, and there is no obvious motivation for the first suggestion. However, there is a possible motivation for the second suggestion: People talk about people most often, and hence, the most likely given (and definite) items are likely to be human. To test this suggestion, we included 16 items like (10) in List 2 of Experiment 1 (the list seen by the second group of 48 participants):

10A. At the game, Frederick bumped into the coach.

Def-An

10B. At the game, Frederick bumped into a coach.

Indef-An

10C. At the game, Frederick bumped into the goal post.

Def-Inan

10D. At the game, Frederick bumped into a goal post.

Indef-Inan

The (A) and (B) forms contained a human goal/recipient in half the items and a human direct object in the other 
half. The (C) and (D) forms contained an inanimate goal/ recipient/object. If there is a pervasive preference for human NPs to be definite, there should be an advantage for (10A) as opposed to (10B), with no comparable advantage for (10C) over (10D). In fact, (10A) was responded to nonsignificantly more slowly than (10B), 3,750 versus $3,683 \mathrm{msec}$, whereas the difference (again nonsignificant) was reversed for (10C) versus (10D), 3,619 versus $3,780 \mathrm{msec}$. Of course, the substantial differences between these items and the materials used in Experiment 1 mean that these data do not provide a completely convincing test of the proposal that the effect observed in Experiment 1 is due to a preference for definite human NPs. However, they certainly do not carry any suggestion that such a preference exists in any robust form, and they encourage us to dismiss the proposal that the Experiment 1 effects simply reflect faster reading of definite than of indefinite human NPs.

The results of Experiment 1 are consistent with Beckman's (1996) definiteness asymmetry condition, which was limited to the double-NP structure. As indicated earlier, they do not allow us to claim that the observed preferences are due to the association between definiteness of NPs and their discourse-givenness, as we have assumed in presenting them. Although it is plausible to assume that definiteness is taken by adult readers to imply givenness, it is in principle possible that the results somehow reflect the anomaly of using a definite NP to introduce an entity into a (nonexistent) discourse context. We believe that adult readers normally have no difficulty accommodating unsupported definite NPs. Nevertheless, Experiment 2 was conducted to evaluate this possibility by presenting each of the 16 experimental sentences from Experiment 1 in a 1 -sentence context that served to make the definite NP of the experimental sentence refer to a given discourse entity; see (11), below. In Experiment 2 , we also reexamined the apparent preference for new-before-given in the NP-PP structure.

\section{EXPERIMENT 2}

\section{Method}

Materials. A pair of 1-sentence contexts was created for each of the 16 experimental items of Experiment 1, illustrated in (11):

11A. All the players were watching an umpire. The pitcher threw the umpire a ball.

11B. The catcher tossed a ball to the mound. The pitcher threw an umpire the ball.

11C. The catcher tossed a ball to the mound. The pitcher threw the ball to an umpire.

11D. All the players were watching an umpire. The pitcher threw a ball to the umpire.

The context sentence introduced an antecedent of the experimental sentence's definite NP into the discourse context, legitimizing its definiteness.

The resulting 16 two-sentence discourses were included in a list of 146 sentences and 2-sentence discourses, of which 36 had a clear anomaly in the final sentence.
Participants and Procedure. Forty-eight University of Massachusetts undergraduates were tested in individual sessions, as in Experiment 1 . The counterbalancing procedures used in that experiment were used in Experiment 2. Other procedures were the same as well, except that the context sentence of the experimental items and the first sentence of the remaining two-sentence discourses were initially presented on one line, with underscore marks on the second line indicating where the letters of the experimental sentence were to appear. When the participant pulled the response trigger, the context sentence disappeared to be replaced by underscores, and the Line 2 underscores were replaced by the letters of the experimental sentence. The participants were told to judge the acceptability of the second (experimental) sentence, given the context sentence, and were told that their time to make this judgment would be timed from the onset of the second sentence (thus, they were under no time pressure to read the first sentence quickly).

\section{Results}

The mean RTs for all responses (after being trimmed as in Experiment 1), and the mean proportion of "accept" responses, appear in Table 2 . The interaction between double object versus NP-PP and given-new order was significant for RT $\left[F_{1}(1,47)=8.74, M S_{\mathrm{e}}=566,180\right.$, $\left.p<.005 ; F_{2}(1,15)=9.923, M S_{\mathrm{e}}=168,195, p<.01\right]$ but not for proportion correct $\left[F_{1}(1,47)=3.75, M S_{\mathrm{e}}=\right.$ $\left.0.023, p<.06 ; F_{2}(1,15)=2.31, M S_{\mathrm{e}}=0.014, p<.15\right]$. Simple effect tests indicated a significant advantage of given-new order for double-object sentences [RT, $t_{1}(47)=$ $3.79, p<.001 ; t_{2}(15)=3.85, p<.001$; proportion correct, $\left.t_{1}(47)=2.05, p<.05 ; t_{2}(15)=2.12, p=.052\right]$. Given-new order did not influence speed or acceptance rate for NP-PP sentences (all $t \mathrm{~s}<1.0$ ). Both main effects (double object vs. NP-PP and given-new order) were significant in the analysis of RTs and the main effect of double-object versus NP-PP was significant in the analysis of proportion correct, but these effects were largely due to the long RT and low acceptance rate for the double-object new-before-given sentences, which was responsible for the interaction.

\section{Discussion}

The advantage observed in Experiment 1 for doubleobject sentences with given-before-new order, as compared with such sentences with new-before-given order, was replicated when definite NPs were in fact given in the discourse context. No such effect appeared for the NP-PP sentences. It seems safe to reject the possibility that these aspects of the Experiment 1 results somehow reflected the anomaly of using a definite NP to refer to an entity that does not exist in a discourse context. Al-

Table 2

Mean Response Times (RTs, in Milliseconds) and Proportion Accepted (P): Experiment 2

\begin{tabular}{|c|c|c|c|c|c|c|c|}
\hline \multicolumn{8}{|c|}{ Condition } \\
\hline \multicolumn{2}{|c|}{ DNP-INP } & \multicolumn{2}{|c|}{ INP-DNP } & \multicolumn{2}{|c|}{ DNP-IPP } & \multicolumn{2}{|c|}{ INP-DPP } \\
\hline RT & $\mathrm{P}$ & $\mathrm{RT}$ & $\mathrm{P}$ & RT & $\mathrm{P}$ & RT & $\mathrm{P}$ \\
\hline 2,620 & 83.4 & 3,301 & 76.4 & 2,656 & 89.6 & 2,578 & 91.2 \\
\hline
\end{tabular}


though it is possible that the effects observed in both experiments are effects of definiteness that arise for some reason other than the association between definiteness and discourse status, we believe that the most straightforward account appeals to the use of definite NPs to refer to given entities.

The advantage of new-before-given order for NP-PP sentences that was observed in Experiment 1 did not appear in Experiment 2. It is possible that the Experiment 1 effect somehow reflected the lack of a discourse context for given items in the NP-PP construction, but we have no clear account of why the particular effect that was observed came about (and we note that in Experiment 1 it was smaller in magnitude and less overwhelmingly significant than the given-before-new advantage for doubleobject sentences). Until the effect is replicated, we believe it is best to rely primarily on the phenomena observed in Experiment 2, where definite NPs did in fact refer to discourse-given entities, and to treat Experiment 1 as simply confirming that the given-before-new advantage was limited to double-object constructions.

The limitation of the observed given-before-new preference to the double-object construction in fact provides some evidence for the suggestion, discussed earlier, that the preference is grounded in a production process rather than reflecting a purely listener-based process such as the presumed lower memory load for given than for new phrases. The latter process provides no clear reason why the preference should be limited to double-object constructions. The memory load of a new NP would be higher than that of a given NP regardless of whether it was followed by another NP or by a PP. However, as suggested in the introduction, a production-based process could account for the asymmetry. The Arnold et al. (2000) data suggest that the unmarked NP-PP construction can felicitously be used for both new-before-given and givenbefore-new orders, whereas the NP-NP construction is largely limited to given-before-new sentences. A writer/ speaker's use of the double-object construction could signal a need to defer uttering a phrase that is relatively inaccessible (e.g., a new phrase). A reader/listener might have trouble justifying and interpreting such a construction if it had no motivation in terms of given-before-new (or heaviness, etc.) The use of the NP-PP construction carries no such implication for the listener.

Experiment 3 was designed to determine whether the preference to have a given NP immediately after the verb in a double-object construction is an absolute preference, or whether it depends on the relative newness of the two phrases (theme and goal/recipient). Evidence presented by Wasow (1997b) indicates that production is influenced by the relative newness of the two phrases. Frequency of the double-object construction does not differ between cases where both phrases are definite and both are indefinite. Experiment 3 extended Experiment 1 to the case where definiteness of the theme was factorially combined with definiteness of the goal/recipient. If comprehension difficulty reflects the needs of the reader (e.g., memory limitations), difficulty should be observed when the initial postverbal NP is indefinite, regardless of the definiteness of the second NP. On the other hand, if comprehension difficulty reflects the same factors that influence production preferences (or if it directly reflects the relative frequency of production), difficulty should be observed only when the first NP is indefinite and the second is definite.

Experiment 3 also extended Experiment 1 by asking whether the given-before-new preference observed for double-object constructions carries over to another construction, the shifted-NP construction (e.g., The pitcher threw to the umpire a badly damaged baseball; cf. [13], below). Arnold et al. (2000) observed (holding phrase length constant) that these constructions were vanishingly infrequent when the theme NP was definite, but occurred roughly $40 \%$ of the time when the theme was indefinite. If readers are sensitive to the factors that induce speakers/writers to produce shifted-NP constructions (or if they are directly sensitive to the frequency of such constructions), the reader may experience difficulty in comprehending a shifted-NP construction in which the indefinite phrase appears before the new phrase.

Thus, Experiment 3 examined the two constructions that were examined in the corpus study of Arnold et al. (2000), the double-object construction already used and a shifted-NP construction. In each case, the experiment examined sentences that honored or violated the presumed given-before-new preference as well as sentences in which both NPs were definite (hence presumably given) or both were indefinite (new), to determine whether there is an independent cost of having the initial NP be indefinite or whether the cost of an initial indefinite NP appears only when it is contrasted with a later definite NP. Experiment 3 differed from Experiment 1 in its use of a self-paced reading task rather than an acceptability judgment task, so that in principle we could check whether the given-before-new preference observed in Experiment 1 for double-object constructions would hold true for another experimental task.

\section{EXPERIMENT 3}

\section{Method}

Materials. Sixteen double-object sentences were constructed by manipulating the definiteness in the objects, illustrated in (12):

12A. The homeowners threw the detective a key to the apartment.

12B. The homeowners threw a detective the key to the apartment.

12C. The homeowners threw the detective the key to the apartment.

12D. The homeowners threw a detective a key to the apartment.

Sixteen shifted object sentences were constructed along the same lines, as in (13):

13A. The pitcher threw to the umpire a badly damaged baseball.

13B. The pitcher threw to an umpire the badly damaged baseball.

13C. The pitcher threw to the umpire the badly damaged baseball.

13D. The pitcher threw to an umpire a badly damaged baseball. 
One of the 16 double-object sentences contained a typographical error and had to be discarded. All items appear in Appendix B. The experimental items were combined with a variety of filler items to constitute a list of 100 items in all. Each experimental item was followed by a two-choice question about the goal/recipient or the theme, to ensure comprehension. Four different counterbalanced lists were constructed, so that (including the one item that had to be discarded) each list contained four items of each construction in each condition and across lists each item was tested in each condition.

Participants and Procedure. Forty-eight University of Massachusetts undergraduates were tested in individual half-hour sessions. A self-paced moving window technique was used. A trial began with a display of underscore marks where each letter was to appear. When the participant pulled a response trigger, these marks were replaced by the letters of the sentence. The participant was instructed to read the sentence quickly yet for comprehension and to pull the trigger again as soon as it was comprehended. Thus, each experimental sentence was read as a whole sentence (but the filler items, which came from separate experiments, were read as two or more separate presentation regions, either full sentences or phrases). Each experimental sentence was immediately followed by a question with two possible answers. The participant indicated a choice by pulling a response trigger under the selected answer. Time to read the sentence was recorded, as was the correctness of the answer to the question.

\section{Results}

Question-answering accuracy ranged from $81 \%$ to $90 \%$ correct across the eight conditions of the experiment, indicating generally satisfactory comprehension of the materials. Mean reading times appear in Table 3. A $2 \times 4$ analysis of variance was conducted with participants and with items as random factors. The experimental factors were sentence structure (double object vs. NP shift) and definiteness (definite-indefinite order, indefinite-definite, definite-definite, and indefiniteindefinite). The effect of sentence structure did not approach significance, nor did the interaction of structure with definiteness (all $F$ s $<1$ ). Definiteness had a highly significant effect $\left[F_{1}(3,141)=8.57, M S_{\mathrm{e}}=411,261\right.$, $\left.p<.001 ; F_{2}(3,87)=6.51, M S_{\mathrm{e}}=172,030, p<.001\right]$. Follow-up $t$ tests with a Bonferroni correction indicated that the definite-indefinite order was generally faster than the other conditions $(p<.01$ for analyses by participants except for the contrast with definite-definite, where $p<.11$; all $p$ s $<.02$ without the Bonferroni correction; by items, $p<.001$ for the comparison with indefinite-definite, $p=.074$ for the comparison with indefinite-indefinite, and $p=.19$ for the comparison with definite-definite; again, all $p<.05$ without the Bonferroni correction). The only other difference that approached significance was the advantage of definitedefinite over indefinite-definite $(p=.062$ by partici-

Table 3

Self-Paced Reading Times (in Milliseconds): Experiment 3

\begin{tabular}{lcccc}
\hline & \multicolumn{4}{c}{ Condition } \\
\cline { 2 - 5 } Structure & Def-Indef & Indef-Def & Def-Def & Indef-Indef \\
\hline Double object & 3,071 & 3,515 & 3,226 & 3,497 \\
NPS & 3,074 & 3,531 & 3,327 & 3,296 \\
$\quad$ Mean & 3,072 & 3,523 & 3,277 & 3,397 \\
\hline
\end{tabular}

pants, $p=.175$ by items; both $p$ s $<.03$ without the Bonferroni correction). In particular, the definite-definite order was essentially identical to the indefinite-indefinite order.

\section{Discussion}

The results of Experiment 3 are informative in two respects. First, while the previously observed advantage of definite-indefinite order in the double-object construction was replicated, no significant differences appeared among the "a-a" and "the-the" conditions. This suggests that the underlying principles resulting in the ordering preferences investigated here regulate the ordering of unlike-arguments - that is, arguments that differ in their givenness/definiteness. Second, the advantage of definiteindefinite order over indefinite-definite order held true for shifted NP sentences as well as double-object sentences. This suggests that the definiteness asymmetry constraint is more general than Beckman (1996) envisioned: It applies more generally than to just doubleobject structures.

As a convenient summary, consider the verb phrase complement schemas in (14). We note that in English a direct object (generally, theme) NP canonically appears immediately after the verb. Given the evidence discussed earlier that phrase-order choices are based on considerations of relative availability of phrases (see also Ferreira \& Dell, 2000; Wasow, 1997a), we suggest that this canonical order can be violated because of production or pragmatic considerations. In particular, if a phrase is relatively inaccessible because of its newness, a construction can be chosen that permits the production of the relatively new phrase to be delayed. Considering only the given/new distinction (e.g., holding phrase length and other factors constant), this means that a double-object construction in which a new goal NP precedes a given theme NP (14B), or in which a shifted NP construction in which a new PP precedes a given NP (14D), apparently violates the principles followed by a speaker/ writer, and therefore would be infelicitous for a listener/ reader (indicated below by \#). However, just as a speaker/ writer needs no special justification to place a new direct object NP in its canonical postverbal position, the reader has no production-based reason to have difficulty comprehending a new-before-given NP-PP sentence (14F):

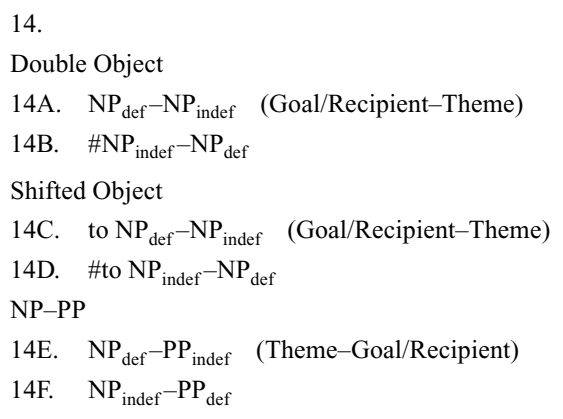

We note that the flexibility offered by the existence of noncanonical structures (shifted NP, double object) suits 
the needs of the language producer by permitting a speaker or writer to delay producing a relatively unavailable argument. It is no surprise, given this sort of production system, that listeners or readers would process sentences more quickly when they honor the needs of the speaker/writer than when they apparently violate them.

\section{CONCLUSIONS}

Is there a general comprehension-based given-new contract? The evidence presented here suggests that there is not. Instead, the present results suggest the importance for the reader of the production-based processes discussed by Wasow (1997b) and Arnold et al. (2000). Other factors held constant, there appears to be a productionbased tendency for some constructions (saliently, the double-object and shifted-NP constructions) to be used only when the construction permits a new/indefinite/inaccessible phrase to be expressed later in a sentence than a phrase that is more given/definite/accessible than it is (or more adequately, in our opinion, to be expressed at a lower position in a structural hierarchy; see note 1). A sentence in which arguments occur in such a construction can "sound right" to a reader/listener if there is a reason for the speaker to have used it (e.g., to delay uttering a new/indefinite and therefore less available argument). On the other hand, a sentence that uses this construction but contains arguments in a new-before-given order somehow "sounds wrong" to the reader/listener: other factors being equal, it is not clear why this phrase order was used. This dispreference for the new-beforegiven order is, however, not completely general. At the very least, it does not hold for the normally preferred, "unmarked," NP-PP construction.

The present results do not allow us to resolve all issues about when the given-before-new order facilitates comprehension. Most saliently, we have not established whether this facilitation simply reflects the relative frequency with which different constructions are produced with this order versus the new-before-given order, or whether comprehension processes are directly influenced by the principles that underlie production processes. We believe that pursuing the latter possibility has the potential of providing insights into comprehension processes that are not permitted if the former frequency-based possibility is accepted.

We must acknowledge, however, that additional research must be conducted before all the necessary details of the presumed production processes can be spelled out. It is not clear, for instance, why a strong production (and comprehension) preference for given-before-new is limited to the double-object and shifted-NP constructions and is not observed for NP-PP constructions. The fact that the former two constructions are "marked" (relatively limited in their distribution) while the latter construction is unmarked may be relevant. An alternative possibility is suggested by the observation that the NP arguments of a verb (or possibly, arguments that receive structural case) constitute the structural "skeleton" of a sentence and that these NP arguments may compete on the basis of relative definiteness (and accessibility, heaviness, etc.) for the highest structural position in a sentence (see note 1). For the moment, we must conclude only that additional research on sentence production should lead to more adequate accounts and that exploring the implications of these accounts for sentence comprehension may provide valuable insights into why some but not all sentences are comprehended more easily when they present given information before new.

\section{REFERENCES}

Arnold, J. E., Wasow, T., Losongco, A., \& Ginstrom, R. (2000). Heaviness vs. newness: The effects of structural complexity and discourse status on constituent ordering. Language, 76, 28-55.

Beckman, J. (1996). Double objects, definiteness, and extraction: A processing preference. In M. Walsh Dickey \& S. Tunstall (Eds.), Linguistics in the laboratory (University of Massachusetts Occasional Papers in Linguistics, Vol. 19, pp. 27-70). Amherst: University of Massachusetts.

Bock, J. K., \& WARrEN, R. K. (1985). Conceptual accessibility and syntactic structure in sentence formulation. Cognition, 21, 47-68.

CARlson, K. (2002). Parallelism and prosody in the processing of ellipsis sentences. New York: Routledge.

Clark, H. H., \& Clark, E. V. (1977). Psychology and language. New York: Harcourt Brace Jovanovich.

Clark, H. H., \& Haviland, S. (1977). Comprehension and the givennew contract. In R. Freedle (Ed.), Discourse production and comprehension (pp. 1-40). Hillsdale, NJ: Erlbaum.

Ferreira, V. S., \& Dell, G. S. (2000). Effect of ambiguity and lexical availability on syntactic and lexical production. Cognitive Psychology, 40, 296-340.

FrAZIER, L., MunN, A., \& Clifton, C., JR. (2000). Processing co-ordinate structures. Journal of Psycholinguistic Research, 29, 343-370.

Halliday, M. A. K. (1967). Notes on transitivity and theme: Part 2. Journal of Linguistics, 3, 177-244.

Henstra, J. (1996). On the parsing of syntactically ambiguous sentences; coordination and relative clause attachment. Unpublished doctoral dissertation, University of Sussex.

KaAn, E. (1998). Sensitivity to NP-type: Processing subject object ambiguities in Dutch. Journal of Semantics, 15, 335-354.

Keenan, E., \& Comrie, B. (1977). Noun phrase accessibility and universal grammar. Linguistic Inquiry, 8, 63-100.

Wasow, T. (1997a). End-weight from the speaker's perspective. Journal of Psycholinguistic Research, 26, 347-362.

WASOW, T. (1997b). Remarks on grammatical weight. Language Variation \& Change, 9, 81-105.

\section{NOTES}

1. Bock and Warren (1985) argue explicitly against the suggestion that more accessible arguments appear earlier in production, demonstrating that accessibility does not influence order in NPs of the form NP and NP. They appeal to a hierarchy in which subject $\rightarrow$ direct object $\rightarrow$ indirect object (Keenan \& Comrie, 1977). However, to account for their data, they have to describe the goal/recipient NP that appears immediately after the verb in a double-object construction as a surface "direct object" but an underlying indirect object. This, at the very least, results in inconsistent usage of the terms "indirect" and "direct" object. We view their data as indicating that more accessible phrases are promoted to higher positions in a hierarchy that is defined by height in a syntactic phrase structure tree, in which subject NP $\rightarrow$ first object NP $(\rightarrow$ second object NP) $\rightarrow$ PP.

2. The pattern of data was essentially the same, but with sometimes lower levels of significance when only "accept" RTs were analyzed and when long responses were eliminated rather than truncated. 


\section{APPENDIX A \\ Materials in Experiment 1}

1. The pitcher threw the umpire a ball.|The pitcher threw an umpire the ball.|The pitcher threw the ball to an umpire.|The pitcher threw a ball to the umpire.

2. The senator mailed the woman a report.|The senator mailed a woman the report.|The senator mailed the report to a woman.|The senator mailed a report to the woman.

3. The student sold the man a car.|The student sold a man the car.|The student sold the car to a man.|The student sold a car to the man.

4. The new teacher gave the pupil a homework assignment.|The new teacher gave a pupil the homework assignment.|The new teacher gave the homework assignment to a pupil.|The new teacher gave a homework assignment to the pupil.

5. The babysitter brought the baby a present.|The babysitter brought a baby the present.|The babysitter brought the present to a baby.|The babysitter brought a present to the baby.

6 . The sergeant promised the recruit a vacation.|The sergeant promised a recruit the vacation.|The sergeant promised the vacation to a recruit.|The sergeant promised a vacation to the recruit.

7. The activist wrote the politician a letter.|The activist wrote a politician the letter.|The activist wrote the letter to a politician.|The activist wrote a letter to the politician.

8.The judge assessed the homeowner a fine.|The judge assessed a homeowner the fine.|The judge assessed the fine to a homeowner.|The judge assessed a fine to the homeowner.

9. The pastor brought the newcomer a cake.|The pastor brought a newcomer the cake.|The pastor brought the cake to a newcomer.|The pastor brought a cake to the newcomer.

10. The traveler sent the child a postcard.|The traveler sent a child the postcard.|The traveler sent the postcard to a child.|The traveler sent a postcard to the child.

11. The butcher promised the woman a rib-roast.|The butcher promised a woman the rib-roast.|The butcher promised the rib-roast to a woman.|The butcher promised a rib-roast to the woman.

12. The scientist showed the assistant an experiment.|The scientist showed an assistant the experiment.|The scientist showed the experiment to an assistant.|The scientist showed an experiment to the assistant.

13. The announcer told the supervisor a lie.|The announcer told a supervisor the lie.|The announcer told the lie to a supervisor.|The announcer told a lie to the supervisor.

14. The writer gave the editor a story.|The writer gave an editor the story.|The writer gave the story to an editor.|The writer gave a story to the editor.

15. The teenager took the old lady a fruit basket.|The teenager took an old lady the fruit basket.|The teenager took the fruit basket to an old lady.|The teenager took a fruit basket to the old lady.

16. The nutritionist sent the man a brochure.|The nutritionist sent a man the brochure.|The nutritionist sent the brochure to a man.|The nutritionist sent a brochure to the man. 
APPENDIX B

Materials in Experiment 3

Double-object structures

1. The director promised $\$ a n \mid$ the $\$$ actress \&a|the\& lead role in the movie.

2. The sheriff gave $\$ a \mid$ the $\$$ deputy \&a|the\& new automatic weapon.

3. The patent office sent $\$ a n \mid$ the $\$$ inventor \&an|the \& incorrect application.

4. The client bought $\$ a n \mid$ the $\$$ assistant \&an|the \& excessively expensive present.

5. The shopkeeper offered $\$ a \mid$ the $\$$ customer \&a|the \& free sample of caviar.

6. The hairdresser brought $\$ a \mid$ the $\$$ client \&a|the \& delicious tasting green tea.

7. The boss gave $\$ a \mid$ the $\$$ manager \&a|the\& well-deserved bonus.

8. The dentist bought $\$ a \mid$ the $\$$ receptionist \&a|the \& big box of chocolates.

9. The neighbor threw $\$ a \mid$ the $\$ \operatorname{dog} \& \mathrm{a} \mid$ the \& fresh tasty bone.

10. The coach told $\$ a \mid$ the $\$$ player \&an|the\& amusing anecdote.

11. The homeowner threw $\$ \mathrm{a} \mid$ the $\$$ detective \&a|the\& key to the apartment.

12. The girl baked $\$ a \mid$ the $\$$ guest \&a|the\& heavily frosted walnut cake.

13. The child made $\$ a \mid$ the $\$$ babysitter \&a|the \& paperclip bracelet.

14. The surgeon knitted \$a|the\$ nurse \&a|the\& beautiful silk scarf.

15. The old-timer carved $\$ a \mid$ the $\$$ tourist \&a|the\& beautiful sea otter.

NPS structures

1. The pitcher threw to \$an|the $\$$ umpire \&a|the\& badly damaged baseball.

2. The senator mailed to $\$ a \mid$ the $\$$ woman $\& a \mid$ the \& controversial report.

3. The student sold to $\$ a \mid$ the $\$$ man \&a|the\& dangerous car.

4. The new teacher gave to $\$ a \mid$ the $\$$ pupil \&a|the \& crazy homework assignment.

5. The babysitter brought to $\$ \mathrm{a} \mid$ the $\$$ baby \&a|the \& lovely present.

6. The pastor brought to $\$ a \mid$ the $\$$ newcomer $\& a \mid$ the \& delicious fruitcake.

7. The traveler sent to $\$ a \mid$ the $\$$ child \&a|the \& very strange postcard.

8. The judge assessed to $\$ a \mid$ the $\$$ homeowner \&an|the\& exorbitant fine.

9. The butcher promised to $\$ a \mid$ the $\$$ woman \&a|the\& special rack of lamb.

10. The pharmacist airmailed to $\$ a \mid$ the $\$$ patient \&an|the\& important prescription.

11. The teenager took to $\$ a n \mid$ the $\$$ old lady \&a|the\& lovely fruit basket.

12. The journalist sent to $\$ a \mid$ the $\$$ magazine \&a|the \& scandalous article.

13. The nutritionist sent to $\$ a \mid$ the $\$$ sick man \&a|the\& brochure about vitamins.

14. The writer gave to $\$ a n \mid$ the $\$$ editor $\& a \mid$ the \& groundbreaking story.

15. The announcer told to $\$ a \mid$ the $\$$ supervisor \&a|the\& disgusting and degrading joke.

16. The scientist showed to $\$ a n \mid$ the $\$$ assistant \&a|the\& secret experiment.

Note—Determiner options indicated by $\$ \ldots \mid \ldots \$$ and \& . . $\mid \ldots \&$. 